\title{
INOVAÇÃO E PARCERIAS ESTRATÉGICAS: O CASO DA FAZENDA REDOMÃO-RS
}

\author{
Innnvation and the strategic partnerships \\ the Fazenda Redomão case - RS
}

Envio 26.03.09 / Aceite 02.08.09

\author{
Adriano Lago ${ }^{1}$ \\ Daniel Arruda Coronel ${ }^{2}$ \\ Letícia Lengler ${ }^{3}$ \\ Tânia Nunes da Silva ${ }^{4}$
}

\section{Resumo}

A inovação em processos, produtos e serviços está sendo considerada, nos últimos anos, uma das forças propulsoras da competitividade, tanto nas organizações quanto nos países, quer seja no ingresso em novos mercados, quer seja na permanência sustentada nos mercados existentes. Seguindo essa perspectiva, o presente estudo objetiva apresentar a inovação baseada em parcerias estratégicas. Para ilustrar, toma-se como caso a atividade bubalina da Fazenda Redomão, em Guaíba, no estado do Rio Grande do Sul, Brasil. Pode-se observar que a estratégia fundamentada em parcerias possibilitou que

1'Doutorando em Agronegócio pela Universidade Federal do Rio Grande do Sul (UFRGS), Mestre em Extensão Rural pela Universidade Federal de Santa Maria (UFSM), Engenheiro Agrônomo pela UFSM, Bolsista de Doutorado do Conselho Nacional de Desenvolvimento Cientifico e Tecnológico (CNPq) e Membro do Grupo de Estudos em Organizações (UFRGS). E-mail: adrianolago@yahoo.com.br

${ }^{2}$ Doutorando em Economia Aplicada pela Universidade Federal de Viçosa (UFV), Mestre em Agronegócio pela UFRGS, Economista pela UFSM, Bolsista de Doutorado da Coordenação de Pessoal de Nível Superior (CAPES) e Membro dos Grupos de pesquisa Comércio Internacional e Cadeias Agroindustriais (UFV) e Integração Regional (UFSM).E-mail: daniel.coronel@ufv.br

${ }_{3}^{3}$ Mestra em Agronegócio pela UFRGS e Administradora pela UFSM. E-mail: Ilenglerworld@yahoo.com

${ }^{4}$ Doutora em Sociologia pela Universidade de São Paulo (USP), Professora dos Programas de Pós-Graduação em Administração e de Agronegócio da UFRGS, e vice-coordenadora do Grupo de Estudo em Organizações (UFRGS). E-mail: tnsilva@ea.ufrgs.br 
o caso estudado tivesse acesso a informações, conhecimentos e capacidades para inovar, tornando-se um centro de referência para a atividade e proporcionando a ampliação dessa rede de parcerias ao longo dos anos.

Palavras-chave: Bubalinocultura; Inovação; Parcerias Estratégicas.

\begin{abstract}
:
Lately, the services, products and processes innovation has been considered one of the propulsion strengths to the competitiveness rather in the organization level or national, trough the entrance in new markets as well as its permanence on it. Following this perspective, this study aims to present the innovation based on strategic partnerships. In order to illustrate it, the bubaline activity from Fazenda Redomão, in Guaíba (Rio Grande do Sul state) was taken as object of study. It's is possible to observe that the strategy of the studied case based on partnerships has acquired information, knowledge and capacity to innovate in a way it has become a reference center to the bubaline activity as well as a possibility of a bigger partnership net over the years.
\end{abstract}

Keywords: Bubalineculture; Innovation;Strategic Partnership.

\title{
1 Introduction
}

A dinâmica dos mercados da atualidade determina, cada vez mais, as regras de inserção e permanência dos novos e atuais participantes. E, dentro dessa dinâmica, a inovação constante em processos, produtos e serviços passa a ser a propulsora e um dos principais fatores de competitividade sustentada.

É com a abertura dos mercados na década de 1990 que o Brasil passou a vivenciar este processo de forma mais intensa, já que novas forças passaram a atuar e a competir diretamente tanto em aspectos tecnológicos como de gestão dos negócios.

Essas mudanças, que provocaram a busca indispensável pela inovação, proporcionaram a abertura das empresas em direção a seu ambiente externo, ou seja, a busca de fontes alternativas de informação e conhecimento, fenômeno este que criou uma verdadeira rede de interação de conhecimentos e informações na busca de soluções para os mercados mais diversos e exigentes. Este processo está baseado na ideia de que a complementaridade de informações, conhecimentos, tecnologias e outros aspectos de diferentes organizações podem produzir patamares superiores de competências em inovação. Essa interação, ou pode-se dizer cooperação, assume as mais diversas formas de acordo com as abordagens dos diferentes autores em cada contexto estudado.

Nessa perspectiva, o presente estudo aborda a inovação em processos e produtos, alcançada a partir da construção de parcerias estratégicas, como é o caso da bubalinocultura, na Fazenda Redomão.

\section{Inovação e parcerias estratégicas}

Nos últimos anos, a globalização e a abertura de mercado provocaram grandes alterações nos cenários internacionais, nacionais, regionais e locais, impulsionados pelo aumento da concorrência bem como pela sua nova dinâmica. 
Com a abertura de mercado, na década de 1990, o Brasil reduziu significativamente seu protecionismo e passou a enfrentar a concorrência internacional, tanto de produtos de baixa qualidade quanto, principalmente, de produtos advindos de países com maiores diferenciais tecnológicos e de inovação.

O processo de inovação não é algo novo, já que, mesmo de forma informal e baseado no empirismo, está presente ao longo da história, na busca da resolução dos mais diversos problemas. A inovação estava ligada diretamente à necessidade, ocorrendo, então, na base da tentativa e erro. Porém, é com o desenvolvimento do conhecimento científico como caminho para a solução de muitos problemas, de forma sistematizada, que a inovação passou a ter um caráter formal e, então, se tornou conhecida científica e até mesmo popularmente como o motor do desenvolvimento.

Ao se expor a essa nova dinâmica de mercado, muitos setores e empresas não conseguiram adaptar-se e inserir-se neste mercado de inovações constantes, em que a competitividade passou a ser a palavra de ordem. Por outro lado, a capacidade de inovar tornase o diferencial entre as empresas que se destacam nessa nova dinâmica de mercado e que se inserem de forma competitiva.

Ao abordar-se a questão da inovação, depara-se com uma diversidade de conceitos aceitos academicamente, dependendo da justificativa ou contexto de sua escolha e uso.

Para Tidd, Bessant e Pavitt (1997, p. 24), "inovação é um processo de transformar oportunidades em novas idéias e colocá-las em amplo uso prático".

Já para Rogers (2003), inovação é uma ideia, método ou objeto que é percebido como novo por um indivíduo ou outra unidade de adoção.

Em Schumpeter (1982), encontra-se a inovação, bem como a tecnologia, como sendo o centro do desenvolvimento tecnológico, as quais devem se tornar viáveis à medida que atendem às necessidades sociais do mercado, no qual a tecnologia é determinada pela economia. E, sendo assim, só haverá desenvolvimento tecnológico se existir demanda por novos produtos e processos produtivos.

O desenvolvimento econômico, para Curcio (2003), efetiva-se a partir de inovações, ou novas combinações de materiais e forças diferentes empregadas de forma diversa, como, por exemplo, a introdução de um novo bem de produção ou uma nova qualidade a um bem previamente existente; abertura de um novo mercado; conquista de uma nova oferta, como por exemplo, de matéria-prima etc.

Curcio (2003), analisando os conceitos de inovação encontrados na literatura, verificou que há pontos em comum, ou seja, para um produto, processo ou serviço ser considerado inovador, é condição indispensável que agregue valor. Assim, o cliente, ao perceber este valor, pode dispor-se a pagar mais por um produto de determinada marca ou escolher outro produto concorrente.

$\mathrm{Na}$ literatura, são reconhecidos alguns níveis de inovações de acordo com o seu impacto, ou seja, inovação incremental e inovação radical.

Para Roberts (1988), a inovação incremental é constituída por pequenas mudanças que surgem da acumulação de experiências na planta, assim como das melhorias de produto e ou processos induzidos logo após uma inovação maior. Ela envolve adaptação, refinamento e/ou avanço de produtos, serviços e/ou de produção. Esse tipo de inovação é a mais comum entre as pequenas empresas e/ou em empresas com baixos investimentos em pesquisa e desenvolvimento.

Já a inovação radical pode ser considerada a atividade criativa, associada à gestão de mudanças tecnológicas maiores. Ou seja, como o próprio nome diz, as alterações são de maior 
impacto, mais radicais e são resultantes de trabalhos dirigidos de pesquisa e desenvolvimento. Sendo assim, são mais frequentes nas empresas maiores, principalmente aquelas que investem fortemente em P\&D (ROBERTS, 1988).

Para Zawislak (1995), uma inovação seria uma nova combinação de conhecimentos para gerar um novo conhecimento que possua valor de troca, e não somente valor de uso e, portanto, passível de ser preferido ou provocar maior dispêndio financeiro por parte do cliente. Para o autor, existiriam dois níveis de inovações, sob o ponto de vista técnico ou tecnológico: as incrementais, que se realizam de forma mais continuadas e são caracterizadas por adaptações e melhoramentos; e as radicais, que causam alterações significativas nas técnicas e tecnologias.

Schumpeter (1982), ao analisar o desenvolvimento a partir da inovação, apresenta cinco possíveis tipos de inovação:

- introdução de um novo bem ou de uma nova qualidade de um bem já existente;

- introdução de um novo método de produção ou de um novo manejo comercial de uma mercadoria;

- abertura de um novo mercado, quer este mercado já tenha existido ou não;

- conquista de novas fontes de suprimento de matérias-primas ou produtos semiindustrializados; e

- estabelecimento de uma nova organização industrial, com criação ou a fragmentação de uma posição de monopólio.

As construções desse autor sobre inovação deixam claro que elas são motivadas pela percepção de oportunidades de mercado que os atores transformam em processo, produtos ou serviços, ou seja, em ganhos econômicos e sociais. Schumpeter (1982, p.170) afirma que,

o empreendedorismo é considerado o fenômeno fundamental do desenvolvimento econômico porque lhe cabe o processo de criação através de novas combinações dos fatores produtivos. A mudança requer liderança, pois fora do fluxo circular, os indivíduos estão desprovidos das regras de conduto para as suas decisões; é mais difícil fazer algo novo do que fazer o que é conhecido e testado pela experiência.

Nesse sentido, o processo inovativo requer qualidades especiais que Schumpeter, em sua primeira versão da teoria (1911), indica estarem presentes em indivíduos especiais, que podemos chamar de empreendedores. Posteriormente, em 1942, ele transportou para as organizações. Essas qualidades ou características especiais podem ser resumidas em: visão, propensão ao risco, capacidade de tomada de decisão frente a um futuro incerto e talento organizacional (BURLAMAQUI e PROENÇA, 2003).

Se as inovações consistem de novas combinações de ideias existentes, capacidades, habilidades e recursos, isso torna o processo de inovação mais complexo, por isso as empresas passam a depender de fontes externas de atividade inovadora, como investimentos em P\&D, redes de cooperação, alianças ou parcerias estratégicas etc.

Nesse sentido, cada vez mais as tendências mundiais de mercados e gestão de processos organizacionais emergentes, além de complexos, tornam-se inviáveis econômica e financeiramente para serem realizados individualmente pelas organizações. Assim, surge, a cada dia, a necessidade de mais instrumentos de cooperação que permitam compartilhar as atividades e conhecimentos da cadeia de valor, tais como os clusters, as redes de empresas e as alianças estratégicas. Dessa forma, é possível, a partir de relações sólidas de longo prazo, obter vantagens colaborativas (PEREIRA, 2006). 
Mediante parcerias estratégicas, é possível viabilizar uma série de necessidades e solucionar muitos problemas que as empresas enfrentam quando atuam de forma individual. Para Amado Neto (2000), é possível combinar competências e utilizar o know-how de outras empresas, compartilhar os custos no desenvolvimento de pesquisas (P\&D) e os conhecimentos adquiridos, realizar experiências em conjunto a fim de diluir os riscos presentes, oferecer produtos de melhor qualidade e diversificação, aumentar as vantagens competitivas, aumentar o poder de barganha nas compras, utilizar mais eficientemente os recursos ociosos de cada um e, até mesmo, juntar forças para uma atuação no mercado internacional.

Dentro dessa mesma perspectiva, Child e Faulkner (1998, p.64) afirmam que,

\begin{abstract}
é a partir do final dos anos 80 que houve um forte crescimento das estratégias de cooperação, principalmente no suporte à inovação. Os autores afirmam que as estratégias de cooperação podem oferecer vantagens colaborativas significantes às organizações sobretudo àquelas às quais faltam competências e recursos, através de complementaridades em ativos, em novos conhecimentos e em aprendizado mútuo. Para que a estratégia de cooperação obtenha sucesso é necessário que haja entre várias empresas a troca de informações, o estabelecimento de um intercâmbio de idéias, o desenvolvimento de uma visão estratégica, a definição clara da área de atuação, a análise conjunta dos problemas e soluções, a definição das contribuições dos parceiros.
\end{abstract}

Essas estratégias de cooperação ou parcerias estratégicas podem tornar-se importantes fontes geradoras de vantagens competitivas sustentadas frente às constantes mudanças de mercado. Neste ambiente em constante mudança, principalmente nos aspectos tecnológicos de inovação em processos e produtos, a cooperação interorganizacional e interinstitucional é base para o sucesso de qualquer organização preocupada com inovação, pois é nessas relações de parceria e cooperação que se pode melhor aproveitar as capacidades individuais de forma coletiva.

\title{
3 Abordagem metodológica
}

O presente trabalho constitui-se em uma pesquisa exploratória. De acordo com Gil (2002), uma pesquisa exploratória envolve levantamento bibliográfico, entrevistas com pessoas que tiveram experiência práticas com o problema pesquisado e análise de exemplos que estimulem a compreensão da situação abordada.

Nesse sentido, adotou-se, como procedimento metodológico, a utilização de dados primários e secundários. Segundo Tachizawa e Mendes (2001, p. 55), "entende-se como dados primários aquelas informações obtidas diretamente no campo ou origem dos eventos pesquisados. Dados secundários, por sua vez, são aqueles obtidos, por exemplo, de obras bibliográficas".

No caso específico deste trabalho, a coleta de dados primários foi feita a partir de uma visita técnica à fazenda Redomão, localizada no município de Guaíba, no estado do Rio Grande do Sul, no dia 07 de outubro de 2008. Nessa propriedade rural, além da visitação e reconhecimento de toda sua estrutura produtiva, realizou-se uma entrevista temática com os proprietários, Erizolei Belmiro Oliveira da Silva e sua esposa Magda Silva, a fim de compreender um pouco mais dessa atividade, das inovações e parcerias estratégicas desenvolvidas. 
Quanto aos dados secundários, utilizou-se de revisão de literatura selecionada, por meio de bibliografia e sites especializados que mencionam a forma de organização coletiva por meio de associações e cooperativas, fundamentadas na cooperação.

Mediante os procedimentos metodológicos utilizados, formou-se um instrumental analítico e prático, que possibilita visualizar as particularidades desse setor que, aos poucos, vem aumentando sua participação na formação do Produto Interno Bruto do Agronegócio (PIB) gaúcho.

\section{Bubalinocultura: produção, mercado e particularidades}

De acordo com o Ministério da Agricultura Pecuária e Abastecimento (MAPA, 2008), e com a Food and Agriculture Organization of the United Nations (FAO, 2008), o Búfalo, Bubalus bubalis, animal de porte avantajado e pelagem preta, teve sua origem na Ásia, sendo, hoje, encontrado em diversos lugares do mundo. Eles chegaram ao Brasil por volta de 1890, na Ilha de Marajó, importados das Filipinas (raça Carabao), que se adaptou e se multiplicou rapidamente.

O búfalo é um animal extremamente rústico e de alta capacidade de adaptação, que pode sobreviver em diversos ambientes, com grandes variações de clima, relevo e vegetação. Ele é revestido por um couro extremamente resistente, espesso e, ao mesmo tempo, muito macio, podendo ser utilizado na produção dos mais diversos artigos, tais como bolsas, sapatos, cintos e até bancos de automóveis de luxo (FAO, 2008).

O fato de os búfalos preferirem lugares pantanosos ou com alguma presença de barro, deve-se a fatores fisiológicos próprios dos bubalinos. A cor preta dos pelos e da pele, propícia à retenção de calor, e o reduzido número de glândulas sudoríparas (perdem pouco calor corpóreo pela transpiração) não atende às exigências para um equilíbrio normal de temperatura corporal. Ao contrário do que se nota no Nelore, que, com a sua barbela repleta de glândulas sudoríparas, consegue fazer termorregulação de forma ideal. Além disso, existem outros fatores naturais para que os búfalos sintam necessidade de frequentar locais úmidos, pantanosos e barrentos, tais como o fato de além de se refrescarem, eliminarem insetos e parasitas (RECHSTEINER, 1994).

A atividade da bubalinocultura na mesma lotação de bovinos de corte pode produzir $17,12 \mathrm{~kg}$ vivo/ha de superfície pastoril a mais do que bovinos de corte. Isso é uma produtividade superior a de bovinos de corte na ordem de $20,70 \%$. Isto é explicado, em parte, pela longevidade da vida produtiva dos ventres búfalos (IRIBARREM e VINHAS, 1994).

Ainda de acordo com Iribarrem e Vinhas (1994), com um rodeio de 20 búfalas (85\% de parição, $80 \%$ de desmame e $2 \%$ de mortalidade), obter-se-ia, ao término de 20 anos, uma produção de 5.857 animais. No mesmo espaço de tempo e igual número de vacas bovinas (com nove anos de vida reprodutiva, 75\% de parição, 70\% de desmame e 5\% de mortalidade), far-se-ia uma produção de 1.375 animais, com uma diferença, pró-búfalos de 4.482 animais.

No Brasil, segundo o MAPA (2008), há quatro raças de búfalos: Carabao, Mediterrâneo, Murrah e Jafarabadi. No Brasil, as quatro raças estão presentes, mas, no estado do Rio Grande do Sul, há apenas três raças, com exceção da raça Carabao.

Atualmente, de acordo com a FAO (2008), grande parte do rebanho mundial (cerca de 95\%) encontra-se na Ásia, destacando-se países como Índia, China e Paquistão como grandes produtores. Na Europa, a Itália é detentora de uma das melhores genéticas leiteiras do mundo.

Os búfalos da raça Mediterrâneo destacam-se na produção de leite e de carne. O Rio Grande do Sul, que conta com três raças de bubalinos - Mediterrâneo, Murrah e Jafarabadi - possui um rebanho aproximado de 250.000 cabeças, distribuídas em vários municípios e 
presente em cerca de 1.000 propriedades rurais. O maior criatório no estado, segundo o último senso realizado pela Associação Sulina dos Criadores de Búfalos (ASCRIBU), possui em torno de 2.500 cabeças, mas a grande maioria dos animais encontra-se distribuída em pequenas e médias propriedades. A quase totalidade destas tem como objetivo a produção de terneiros ou de animais para corte, sendo, ainda, reduzido o número de propriedades dedicadas à produção de leite (MAPA, 2008).

O mercado para os derivados alimentícios do búfalo está em alta, visto que, atualmente, se observa uma tendência mundial na procura por saúde, mediante o consumo de alimentos ricos em proteínas de alto valor, com baixos teores de colesterol e livres de resíduos químicos. Assim, o búfalo surge como uma alternativa viável de proteína vermelha, contendo $40 \%$ menos colesterol, 12 vezes menos gordura, 55\% menos calorias, $11 \%$ a mais de proteínas e $10 \%$ a mais de minerais, quando comparado à carne bovina (FAO, 2008).

Observa-se que os produtores desses animais estão preocupados com a competitividade dos alimentos no mercado quando comparado a outras carnes e outros tipos de leite. Por isso, muitos produtores procuram se unir para terem mais escala de produção e também para trocar ideias sobre o modo de produção e as novidades de produtos para colocar na mesa dos consumidores. Um exemplo disso é a Fazenda Redomão, localizada em Guaíba, no estado do Rio Grande do Sul, Brasil.

O Rio Grande do Sul foi o estado pioneiro, no Brasil, a colocar a carne de búfalo embalada a vácuo em redes de supermercado. Já na década de 1990 os consumidores de Porto Alegre tiveram à sua disposição cortes de traseiro embalados individualmente. Hoje as principais redes de supermercados de Porto Alegre, Grande Porto Alegre e Litoral (durante o veraneio), oferecem carne de búfalo embalada a vácuo. Igualmente diversas cidades do interior do Estado têm programas de fomento do consumo da carne bubalina, oriunda do abate de novilhos jovens (ASCRIBU, 2008).

\section{Inovação e parcerias estratégicas na bubalinocultura: o caso da Fazenda Redomão}

A inovação e a formação de parcerias estratégicas tornaram-se fatores necessários e indispensáveis para a grande maioria dos empreendimentos ou empresas com qualquer atuação no mercado formal e, até mesmo, informal. Dentro dessa perspectiva da inovação e das parcerias estratégicas, toma-se a Fazenda Redomão como um caso a ser estudado dentro do Agronegócio. A Fazenda Redomão é, hoje, um centro de excelência em bubalinocultura e produz búfalos das raças Mediterrâneo e Murrah há 12 anos, dentro de um sistema de pastoreio denominado Pastoreio Racional Voisin ${ }^{5}$, sendo a pioneira na América Latina a implementar este sistema com bubalinos.

A propriedade iniciou sua atividade bubalina fazendo recria e engorda dentro do sistema convencional de manejo dos animais e com a utilização de fertilizantes químicos e medicamentos convencionais. Nesse período inicial, segundo o proprietário, verificava-se prejuízos constantes com a atividade. Esse processo que durou quatro anos.

O proprietário, não percebendo melhorias com o sistema adotado, passou a se dedicar-se ao estudo da utilização de búfalos na produção de leite e, posteriormente, seus

${ }^{5}$ Para maiores informações sobre a filosofia e os procedimentos agronômicos do Pastoreio Voisin, ver Sorio Junior (2003). 
derivados. Um longo período de constante busca por conhecimento, troca de experiências, viagens nacionais e internacionais, formação de parcerias com diversas instituições, tornou a fazenda atualmente especializada em genética, utilizando inseminação artificial, com sêmen dos melhores touros do "Índice Genético Bufale e Tori", da Itália.

O Pastoreio Racional Voisin para búfalos é outra inovação na fazenda, pois é um sistema que preconiza a rotação de pastagens, buscando o equilíbrio entre a oferta e a necessidade dos animais, equilibrando e harmonizando a vida de ambos. Essa técnica consiste em piquetear a propriedade em pequenas parcelas; no caso da Fazenda Redomão, os piquetes são de 0,5 hectares, onde os animais pastejam de acordo com a oferta de matéria seca (oferta de alimento disponível para o animal) previamente calculada. Segundo o proprietário da fazenda, o pastoreio contínuo traz degradação das pastagens pela ação contínua do animal, o que não ocorre com o uso do Pastoreio Voisin.

A área da propriedade é de 608 hectares, onde são criados de 400 a 600 búfalos, dependendo da oferta de alimento. São 328 piquetes, divididos em sete setores, diferenciados por cores. As divisões dos setores são feitas com 72.000 metros de arame de cerca elétrica e objetivam dividir os animais em lotes diferenciados, conforme seu peso e idade. De 4 em 4 meses todos os animais são pesados e é feita uma nova seleção.

O uso de tecnologias limpas consiste em criar os animais em pastagem natural, sem o uso de agrotóxicos ou qualquer outro produto químico, ou seja, sem aportes externos à propriedade. O Pastoreio Racional Voisin propicia que todos os dejetos produzidos pelos animais sejam incorporados na forma de adubo nas pastagens. A fazenda faz a exploração ecológica do búfalo para a preservação ambiental, pela viabilidade econômica, pelo bem-estar animal e porque, hoje, o mercado consumidor está exigindo produtos livres de contaminantes químicos. Dentro desse sistema é realizado um rigoroso tratamento profilático dos animais em parceria com a Universidade Federal do Rio Grande do Sul (UFRGS) e a Universidade Luterana do Brasil (ULBRA-Guaíba), em que os animais são examinados para verificar sua sanidade e medicação. A vacinação obrigatória é realizada regularmente.

O proprietário, quando foi questionado durante a visita técnica sobre por que escolheu trabalhar com búfalos, respondeu que é um animal de fácil adaptação, tem maior conversão alimentar do que os bovinos devido à digestibilidade de celulose, seus produtos têm um alto valor no mercado e é um melhorador de campo, já que não faz dieta seletiva (seu sistema bucal não permite a seleção de pastagens).

Segundo o proprietário, a consolidação de sua fazenda não foi um processo realizado da "noite para o dia", mas um longo caminho percorrido, desde a busca de conhecimento sobre uma atividade pouco conhecida e estudada, mas o seu ideal empreendedor e a visão da necessidade de buscar algo inovador guiaram os seus avanços na atividade.

As parcerias estratégicas foram apresentadas como fator de sucesso na trajetória da fazenda, as quais podem ser assim relacionadas: criadores de búfalos de todo o Brasil (troca de conhecimento e genética animal), Cooperativa de Produtores de Búfalos do Estado do Rio Grande do Sul (COOPERBÚFALO), Universidade Luterana do Brasil (ULBRA), Universidade Federal do Rio Grande do Sul (UFRGS), Universidade de Passo Fundo (UPF), Serviço de Apoio às Micro e Pequenas Empresas (SEBRAE-RS), Serviço Nacional de Aprendizagem Rural (SENAR) e outras parcerias.

Com a parceria de produtores, Cooperativa, Associação Brasileira de Criadores de Búfalos (ABCB), conseguiram, com o Ministério da Agricultura, no ano de 2001, a liberação da importação de sêmen bubalino mediterrâneo de genética leiteira. 
No que diz respeito à ideia de parcerias, o proprietário explicou que o objetivo é ter mais criadores aptos para participarem do mercado, bem como serem divulgadores da carne, leite e derivados de búfalos. Para ele, quanto mais produtores engajados nesta atividade, maior espaço e reconhecimento a mesma terá, por isso, orgulha-se de já ter recebido mais de 3.000 visitantes, entre, estudantes, pesquisadores nacionais e internacionais, criadores e autoridades. Nesse processo de interação, há muita troca de conhecimentos, o que solidifica a atividade.

$\mathrm{Na}$ área de inovação, pode-se destacar a inovação em processos no caso da forma de criação através do sistema Voisin, que, até então, era utilizado somente para bovinos; o melhoramento genético, que proporcionou um aumento na produção leiteira; e a produção ecologicamente equilibrada pela utilização de insumos internos à propriedade.

Outros aspectos importantes a serem destacados foram a utilização de esterco dos animais para a produção de húmus utilizado na horta e pomares da fazenda e a produção, em um viveiro especialmente construído, de mudas para reflorestamento da fazenda, como forma de proporcionar sombra para os animais, projeto que já atingiu 12.000 mudas implantadas até 2008.

\section{Considerações finais}

Ao considerar o processo de inovação como fator de conquista e manutenção da competitividade de uma organização e, até mesmo, de uma nação, deve-se percebê-lo de forma integrada a uma nova dinâmica, ou seja, a inovação não pode e não ocorre de forma isolada nas empresas, principalmente em se tratando de pequenas e médias empresas.

É nesta perspectiva que, no caso estudado, verificou-se e foi destacado pelos entrevistados que a formação de parcerias estratégicas é fator fundamental para o desenvolvimento e consolidação de inovações, quer sejam radicais ou incrementais.

Outro aspecto relevante é que a inovação se consolida sobre uma base sólida de conhecimento acumulado, como se pode perceber no caso estudado, em que o proprietário despendeu anos de estudos, parcerias, experimentos para consolidar um conhecimento capaz de inovar a atividade bubalina, conhecimento este adquirido e compartilhado com os demais integrantes da rede de parceria. 


\section{Referências}

\section{AMADO NETO, J. Redes de cooperação} produtiva e clusters regionais: oportunidades para pequenas e médias empresas. São Paulo: Atlas/Fundação Vanzolini, 2000.

ASCRIBU. Associação Sulina de Criadores de Búfalos. Disponível em: <http://www.ascribu. com.br>. Acesso em: 10 nov. 2008.

BURLAMAQUI, L.; PROENÇA, A. Inovação, recursos e comprometimento: em direção a uma teoria estratégica da firma. Revista Brasileira de Inovação, v. 2, n. 1, p.79-110, jan./jul., 2003.

\section{CHILD, J.; FAULKNER, D. Strategies of} cooperation: managing alliances, networks and joint ventures. New York: Oxford University Press, 1998.

CURCIO, L. A. O processo de inovação em pequena empresa. 2003. 118f. Dissertação (Mestrado Profissionalizante em Administração) Programa de Pós-Graduação em Administração, Escola de Administração - Universidade Federal do Rio Grande do Sul, Porto Alegre, 2003.

FAO. Food and Agriculture Organization of the United Nations. Disponível em: <http://www. fao.org >. Acesso em: 05 set. 2008.

FAZENDA REDOMÃO. Disponível em: <www. redomao.com.br> Acesso em: 09 de dez., 2008.

\section{GIL, A. C. Técnicas de pesquisa em economia} e elaboração de monografias. 4. ed. São Paulo: Atlas, 2002.

IRIBARREM, C. B.; VINHAS. J. N. I. O búfalo e sua rentabilidade: análise técnica e econômica comparativa entre búfalos e bovinos de corte. In: FEDERACITI; V ASCRIBU. O búfalo e sua rentabilidade. Guaíba: Agropecuária, 1994.91p. MAPA. Ministério da Agricultura, Pecuária e Abastecimento. Estatísticas. Disponível em:
$<$ http://www.agricultura.gov.br>. Acesso em: 28 nov. 2008.

PEREIRA, B. A. D. Estruturação de relacionamentos horizontais em rede. 2006, 218f. Tese (Doutorado em Administração) Programa de Pós-Graduação em Administração - Escola de Administração, Universidade Federal do Rio Grande do Sul, Porto Alegre, 2006.

RECHSTEINER, E. Manejo de campo. In: FEDERACITI; V ASCRIBU. O búfalo e sua rentabilidade. Guaíba: Agropecuária, 1994. 91p.

ROBERTS, E.B. Managing invention and innovation. Research and Technology Management, Washington, p. 11-29, Jan./Feb. 1988.

ROGERS. E. Diffusion of innovations. New York: The Free, 2003.

SCHUMPETER, J. A. Teoria do desenvolvimento econômico: uma investigação sobre lucro, capital, crédito, juro e o ciclo econômico. São Paulo: Abril Cultural, 1982.

SORIO JUNIOR, H. Pastoreio Voisin: teorias, práticas, vivências. Passo Fundo: UPF, 2003.

TACHIZAWA, T.; MENDES, G. Como fazer monografia na prática. 6 . ed. Rio de Janeiro: FGV, 2001.

TIDD, J.; BESSANT, J.; PAVIT, K. Managing innovation: integrating technological, market and organizational change. Chichester, UK: John Wiley, 1997.

ZAWISLAK, P. A. A relação entre o conhecimento e desenvolvimento: essência do progresso técnico. Análise, v.6, n.1, p.125-149, 1995. 